\title{
Eksplorasi dan Uji Keragaan Parasitoid Penggerek Buah Kapas Pectinophora gossypiella Saunders (Lepidoptera: Gelechidae)
}

\author{
Nurindab, D.A. Sunarto, dan Sujak \\ Balai Penelitian Tanaman Tembakau dan Serat \\ 11. Raya Karangploso Kotak Pos 199 Malang
}

\begin{abstract}
Pink bollworm, $P$. gargpiella, is a main pest of cotton that causes boll damage up to $70 \%$. Recommended IPM has nor effectivcly control this pest. The use of parasitoids of this pest is one of strategy to manage this pest population as using chemical control is expensive and caused secondary pest. This research objective is to study some biological aspects of pink bollworm parasitoids by doing exploration of the parasitoids in cotton growing areas and testing the potential candidates as biocontrol agents. The activity was conducted from April - December 2001. The research was conducted in two steps: survey and laboratory tests. The survey was conducted in East Java (Asembagus and Lamongan), Central Java (Brebes) and South Sulawesi (Bone) by collecting pink bollworm eggs and identifying the emerged parasitoids, Laboratory tests were done in Biological Control Laboratory of ITFCRI, Malang, consists of reproductive performance aspects. We found rwo and five species of egg and larval parasitoids, respectively. Parasitism level of egg was $81 \%$ by Tribogrammatoidea spp. and that of larva was $24 \%$ by Apanteles sp. These two parasitoids are predominant and found in all cotton growing areas. Tribogrammatoidea spp. have opportunity to be used as biocontrol agent in relcase program, while Apanteles sp. would have valuable role in conservation approach.
\end{abstract}

Key Word: Gossypium birsutum, Pectinophora gossypiella, Trichogrammatoidea, Apanteles

\section{PENDAHULUAN}

Penggerek buah kapas merah muda P. gossypiel/a merupakan serangga hama utama kapas yang pada lima tahun terakhir ini menimbulkan kerugian yang besar bagi petani kapas. Serangga hama ini juga merupakan serangga hama utama tanaman kapas di negara-negara penghasil kapas di dunia. Serangga penggerek buah ini jika tidak dikendalikan dan tidak ada penekanan populasinya oleh musuh-musuh alaminya dapat menyebabkan kerusakan buah hingga $70 \%$. Pada pertanaman kapas di Grobogan
Jawa Tengah, serangan serangga hama ini menimbulkan kerugian hingga $60 \%$ (petani kapas Desa Gabes, Grobogankomunikasi pribadi). Pada pertanaman kapas yang waktu tanamannya terlambat hingga 30 hari, serangan serangga hama ini pada buah dapat mencapai $92 \%$ (Sangareddy and Patil, 1997).

Rakitan teknologi PHT yang direkomendasikan masih belum dapat secara efektif mengendalikan scrangga hama ini, karena hama ini terdapat di tempat yang terlindung, yaitu di dalam bunga atau buah, schingga insektisida tidak dapat menjangkaunya. Mahalnya penerap- 
an teknik pengendalian kimiawi, terjadinya masalah hama sekunder dan pertimbangan uncuk melestarikan lingkungan menyebabkan diperlukannya strategi pengelolaan hama yang berorientasi ekologi terhadap penggerek buah ini (Henneberry and Naranjo, 1998).

Untuk pengendalian secara hayat, penggunaan parasitoid merupakan salah satu alternatif yang banyak dibahas, sebab penggunaan kelompok agensia hayati yang lain (patogen dan predator) tidak memberikan hasil yang meyakinkan (Gordh and Ellington, 2001), walaupun Sholahuddin (2001) melaporkan bahwa tingkat mortalitas telur $P$. gossypiella di laboratorium oleh pemangsanya dapat mencapai $70 \%$.

Usaha pengendalian hayati yang telah dilakukan adalah eksplorasi musuh alami P. gosopiella selama 60 tahun di daerah-daerah yang diduga merupakan asal dari serangga hama ini, yaitu Afrika, Eropa dan India (Common, 1958; Legner and Medved, 1979). Introduksi musuh alami dari daerah tersebut ke daerah-daerah endemik tidak memberikan hasil yang nyata. Baru-baru ini, eksplorasi musuh alami dialihkan ke daerah Australia, Malaysia dan Indonesia dan spesies-spesies parasitod yang diintroduksi memberikan hasil yang menjanjikan (Legner and Bollows, 2000). Usaha pemanfaatan parasitoid di negara-negara yang endemik serangga hama ini dengan memanfaatkan parasitoid-parasitoid asli negara tersebut dilaporkan dapat berhasil dengan baik (Havez and Nada, 2000).
Oleh karena itu, ekspolorasi dan pemahaman bioekologi parasitoid-parasitoid asli Indonesia yang menyerang $P$. gossypiella merupakan hal mendasar yang perlu dilakukan dalam program pengendalian hayati $P$. gossypiella untuk menunjang PHT kapas.

Penelitian ini bertujuan untuk mempelajari beberapa aspek biockologi parasitoid $P_{+}$gosspiella dengan melakukan eksplorasi parasitoid $P$. gossypiella di daerah pengembangan kapas dan pengujian kandidat parasitoid untuk menenrukan pendekatan yang sesuai dalam memanfaatkan parasitoid ini dalam program pengendalian hayati $P$. gossyple/ls pada kapas.

\section{BAHAN DAN METODE}

\section{Waktu dan Tempat}

Penelitian ini dilakukan pada April - Desember 2001. Dalam penelitian dilakukan dua kegiatan yaitu survei parasitoid dan uji laboratorium. Survei parasitoid dilakukan di Jawa Timur (Asembagus dan Iamongan), Jawa Tengah (Brebes) dan Sulawesi Selatan (Bone). Uji laboratorium dilakukan di Laboratorium Pengendalian Hayati (Parasitoid \& Predator) Balittas, Malang.

\section{Survei Parasitoid}

Survei parasitoid dilakukan dengan mengumpulkan telur dan larva $P$. gossypiella dari lapang, yaitu dari tanaman kapas dan tanaman inang lainnya yang terdapat di sekitar pertanaman kapas. 
Hasil koleksi tersebut kemudian dipelihara di laboratorium dan parasitoid yang muncul diperbanyak dengan menggunakan inang yang dipelihara di laboratorium untuk keperluan identifikasi. Lntuk setiap daerah dilakukan pengumpulan sekurang-kurangnya dua kali selama musim tanam kapas dalam fase generatif (50 - 80 hari setelah tanam). Identifikasi parasitoid telur dibantu oleh Dr. J. Pinto dari LC Riverside. Identifikasi parasitoid larva dilakukan dengan menggunakan kunci determinasi yang dipublikasikan olch Commonwealth Inscitute of Entomology (CIE).

\section{Pengujian di Laboratorium}

Kegiatan penelitian di laboratorium dilakukan untuk menguji keragaan reproduksi serta potensi parasitoidparasitoid yang berpotensi tinggi untuk digunakan sebagai agensia hayati bagi $P$. gossypiella. Dalam penelitian ini yang diuji adalah parasitoid telur Trichogrammatoidea spp. dan parasitoid larva Apanteles sp. L $\mathrm{ji}$ tersebut meliputi uji preferensi parasitoid teradap beberapa stadia $P$. gossypiel/a, potensi reproduksinya serta biologinya.

\section{Uji keragaan reproduksi parasitoid.}

Dalam uji ini dilakukan pengamatan biologi yang ditekankan pada aspek reproduksi parasitoid pada Conyra rephalonica (inang pengganti) dan $P$. gossypiella (inang asli). Untuk setiap spesies digunakan $10-22$ individu parasitoid. Pengamatan dilakukan dengan mengamati lama hidup parasitoid, ke- mampuan memarasit inang/betina, jumlah progeni dan sex rationya. Pemaparan inang kepada parasitoid dilakukan selama parasitoid tersebut hidup dan inang yang dipaparkan diganti dengan inang yang baru setiap 24 jam.

\section{Uji preferensi parasitoid}

Lii preferensi parasitoid dilakukan untuk mengetahui stadia dan jenis inang yang sesuai unuk perkembangan parasitoid. Dalam uji ini dilakukan uji dengan pilihan (thotic test). Pada uji ini ditawarkan beberapa stadia/jenis inang pada seekor parasitoid selama 30 menit dan diamati terjadinya oviposisi. Terjadinya parasitasi pada telur inang dapat dilihar dengan adanya perilaku pengeboran inang (drilling) yang diteruskan dengan oviposisi yang ditandai dengan gerakan abdomen tertentu Nurindah et al, 1999). Terjadinya parasitasi pada larva dapat dilihat dengan terjadinya sengatan parasitoid pada tubuh inangnya.

\section{HASIL DAN PEMBAHASAN}

\section{Survei Parasitoid}

Dari hasil survei ditemukan dua spesies parasitoid telur dan lima spesies parasitoid larva yang semuanya tergolong dalam Ordo Hymenoptera. Klasifikasi parasitoid-parasitoid tersebut tersaji pada Tabel 1. Penyebaran parasitoid tersebut di daerah survei tersaji pada Tabel 2.

Dari jenis parasitoid yang ditemukan, parasitoid telur merupakan parasitoid yang persentase parasitasinya ting. 
gi (Tabel 3). Apanteles sp. merupakan parasitoid larva yang menyebabkan mortalitas teruinggi dibandingkan parasitoid larva lainnya. Oleh karena itu, parasitoid Tribogrammatoidea spp. dan Apanteles sp. adalah dua parasitoid yang akan diuji kelayakannya sebagai kandidat agen hayad pada kegiatan selanjutnya.

\section{Pengujian Laboratorium}

\section{Parasitoid Telur}

Uji Keragaan Reproduksi. Uji keragaan reproduksi parasitoid telur $P$. gosoptella dilakukan dengan menggunakan telur Congra cephalonica (inang pengganti). Beberapa parameter keragaan reproduksi Tridogrammatoidea spp. pada telur C. cephalonica tersaji pada Tabel 4.

Uji Preferensi. Uji preferensi yang dilakukan adalah preferensi para-

Tabel 1. Klasifikasi parasitoid $P$. gossypiella dari beberapa daerah pengembangan kapas di Indonesia.

\begin{tabular}{llll}
\hline \hline Ordo & Famili & Spesies & Stadia inang \\
\hline Hymenoptera & Trichogrammatidae & Trichogrammatoidea amigera & Telur \\
& Braconidae & Apanteles sp. & Larva \\
& Chalcididae & Bracon sp. & Larva \\
& IChneumonidae & Spesies-1 & Larva-pupa \\
& Larva-pupa \\
\hline
\end{tabular}

Tabel 2. Penyebaran parasitoid pada $P$. gossypiefla di daerah pengembangan kapas di Indonesia.

\begin{tabular}{|c|c|c|c|c|}
\hline \multirow{2}{*}{ Spesies } & \multicolumn{2}{|c|}{ Jawa Timur } & \multirow{2}{*}{$\begin{array}{l}\text { Jawa Tengah } \\
\text { (Brebes) }\end{array}$} & \multirow{2}{*}{$\begin{array}{c}\text { Sulawesi Selatan } \\
\text { (Bone) }\end{array}$} \\
\hline & Lamongan & Asembagus & & \\
\hline T. armigera & + & + & & \\
\hline $\begin{array}{l}\text { T. bactrae } \\
\text { Apanteles sp. }\end{array}$ & $\begin{array}{l}+ \\
+\end{array}$ & $\mp$ & - & + \\
\hline Bracon sp. & - & + & . & - \\
\hline Brachymeria sp. & + & + & + & - \\
\hline Ichneumonidae & - & + & - & . \\
\hline
\end{tabular}

+ : ditemukan - : tidak ditemukan ? : tidak diamati

Tabel 3. Parasitisasi telur dan larva P. gossypiella di beberapa daerah pengembangan kapas.

\begin{tabular}{|c|c|c|c|c|c|c|c|c|}
\hline \multirow{2}{*}{ Lokasi } & \multirow{2}{*}{$\begin{array}{c}\text { Jumlah } \\
\text { pengumpulan } \\
\text { inang (n) }\end{array}$} & \multicolumn{5}{|c|}{$\%$ Parasitasi oleh } & \multicolumn{2}{|c|}{$\begin{array}{c}\text { Total } \\
\text { parasitasi }\end{array}$} \\
\hline & & $\begin{array}{c}\text { Trichogramma- } \\
\text { toidea spp. }\end{array}$ & Apanteles & Brachymeria & Bracon & $\begin{array}{l}\text { Ichneu- } \\
\text { monidae }\end{array}$ & Telur & Larva \\
\hline \multirow[t]{5}{*}{ Asembagus } & 126 & 65,0 & - & - & - & - & 65,0 & - \\
\hline & 114 & 69,0 & $\therefore$ & $\therefore$ & - & : & 69,0 & - \\
\hline & 819 & - & 8,4 & 2.6 & 1,3 & 0 & - & 12,3 \\
\hline & 527 & - & 6.1 & 2,7 & 0 & 0 & - & 8,8 \\
\hline & 93 & $\therefore$ & 4,3 & 1.1 & 0 & 0 & - & 5,4 \\
\hline \multirow[t]{4}{*}{ Lamongan } & 486 & 81.7 & - & $\therefore$ & - & - & 81,7 & - \\
\hline & 172 & - & 7,0 & 16.3 & 0 & 2,3 & $\cdot$ & 25,6 \\
\hline & 456 & - & 23,9 & 13,4 & 0 & 0,4 & - & 37,7 \\
\hline & 2466 & - & 10,7 & 3,4 & 0 & 0,2 & - & 14,1 \\
\hline \multirow[t]{2}{*}{ Brebes } & 678 & - & 0,4 & 0.2 & 0 & 0 & - & 0.6 \\
\hline & 534 & - & 0.8 & 0,1 & 0 & 0 & - & 0.9 \\
\hline \multirow[t]{2}{*}{ Bone } & 13 & - & 8,8 & 0,2 & 0 & 0 & - & 9,0 \\
\hline & 124 & - & 2,0 & 0 & 0 & 0 & - & 2,0 \\
\hline
\end{tabular}


sitoid terhadap jenis inang dengan pilihan. Jenis inang yang digunakan adalah telur P. gossypiella dan H. armigera. Pemilihan telur H. armigera dalam uji ini adalah dengan pertimbangan bahwa pada waktu yang sama di pertanaman kapas dapat ditemukan kedua telur serangga hama ini. Tribogrammatoidea armigera (asal Lamongan) memperlihatkan preferensi yang tinggi terhadap telur $P$. gossypiella daripada telur $H$. armigera (Tabel 5), sedangkan $T$. armigera (asal Asembagus) tidak memperlihatkan preferensi yang berbeda antara telur $P$. gorsypiella dan $H$. armigera.

\section{Parasitoid Larva}

Uji Keragaan Reproduksi. Uji keragaan reproduksi parasitoid larva Apanteles sp. pada larva inang asli maupun pengganti tidak didapatkan data yang seperti diharapkan, karena setelah oviposisi pada inangnya, parasitoid tidak dapat berkembang dengan baik. Dari 46 oviposisi yang terjadi pada larva $P$. gossypiella dan 65 oviposisi pada larva $C$. cephalonica hanya didapatkan progeni parasitoid masing-masing 5 ekor (23 jantan dan 2 betina) dan 3 ekor ( 1 betina dan 2 jantan). Olch karena itu, masih diperlukan metode yang sesuai untuk mengamati keragaan reproduksi parasitoid ini. Data keragaan reproduksi yang dapat disajikan adalah seperti pada Tabel 6 .

Uji Preferensi. $\mathrm{L}_{\mathrm{ji}}$ preferensi yang telah dilakukan adalah uji preferensi parasitoid Apanteles sp. rerhadap beberapa stadia larva $P$. gosspiella dan C. cephalonica pada uji de- ngan pilihan dan tanpa pilihan. Preferensi diamati dari jumlah inang yang diparasit (parasitoid menyengat inang) dan terjadi oviposisi.

Apanteles sp. menunjukkan preferensi yang sama terhadap stadia inang, yaitu larva instar II dan III (Tabel 7). Pada uji dengan pilihan, preferensi parasitoid lebih tinggi terhadap larva $P$. gossypiella dibandingkan dengan larva $C$. cephalonica. Sedangkan pada uji tanpa pilihan, jumlah oviposisi pada stadia inang yang sesuai tidak menunjukkan perbedaan yang nyata.

Telur P. gossypiel/a dapat diparasit oleh sedikitnya dua spesies Trichogrammatoidea. Trichogrammatoidea armigera merupakan new bost report, karena belum pernah dilaporkan memarasit $P$. gossypiella. Status ini merupakan informasi penting bagi peneliti-peneliti di seluruh dunia yang bekerja di bidang pengendalian hayat, terutama yang spesialisasinya parasitoid telur dari famili Trichogrammatidae dan memfokuskan penelitiannya pada parasitoid telur P. gossypiel/a. Spesies parasitoid telur Trichogrammatoidea yang pernah dilaporkan adalah $T$. batrae berasal dari Australia dan India (Hassan, 2001). Parasitoid telur ini pernah diintroduksikan ke California, Arizona dan New Mexico pada tahun 1986 dan dilepas pada 1992, untuk mengendalikan $P$. gossypiella (Naranjo, 1993).

Diantara dua spesies parasitoid telur yang ditemukan, $T$. armigera dominan terhadap $T$, bactrae. Spesies yang pertama ditemukan di Lamongan 
dan Asembagus, sedangkan spesies yang kedua hanya ditemukan di Lamongan. Tingkat parasitasi alami parasitoid telur ini cukup tinggi, yaitu $65-82^{\circ} \%$ (Tabel 2 ). Walaupun demikian, kerusakan yang terjadi karena $P$. gossypiella masih tinggi, yaitu $70 \%$ (di Asembagus) dan $85 \%$ (di Jamongan). Keadaan yang demikian disebabkan katena parasitasi yang tinggi tersebut terjadi pada puncak populasi $P$. gossppiella generasi kedua.

Sclama musim tanam kapas terdapat dua generasi P. gosigpiella (Rizal et al, 1999). Generasi pertama dimulai pa- da saat tanaman mulai berbunga dan generasi kedua pada 65-90 hari setelah tanam (hst). Parasitasi telur yang terjadi pada populasi generasi pertama sangat rendah, sehingga mortalitas yang terjadi juga rendah dan berakibat meningkatnya kelimpahan populasi pada generasi kedua, vairu hingga 1,5 kali dari generasi pertama. Dengan fenomena ini, maka untuk dapat memanfaatkan potensi parasitoid telur tersebut, perlu dilakukan augmentasi dengan teknik inundasi atau inokulasi pada generasi pertama $(35-45$ hst). Pelepasan T. armigera pada waktu

Tabel 4. Keragaan reproduksi parasitoid telur pada $P$ gossypiella asal Lamongan dan Asembagus.

\begin{tabular}{lccccc}
\hline \hline Parasitoid telur & $\mathrm{N}$ & $\begin{array}{c}\text { Lama hidup } \\
\text { (har) }\end{array}$ & $\begin{array}{c}\text { Kemampuan memarasit } \\
\text { inanglbetina }\end{array}$ & $\begin{array}{c}\text { Jumlah } \\
\text { progeni }\end{array}$ & $\begin{array}{c}\text { Sex Ratio } \\
\text { (B/J) }\end{array}$ \\
\hline T. armigera (Asembagus) & 22 & 15,6 & 123,0 & 80,9 & 0,60 \\
$T$ armigera (Lamongan) & 24 & 18,0 & 127.2 & 82,4 & 0,67 \\
T. bactrae & 10 & 15.2 & 133,4 & 84,6 & 0,87 \\
\hline
\end{tabular}

Tabel 5. Rata-rata peletakan telur $=$ standard error $T$. armigera asal Lamongan dan Asembagus pada telur $P$ gossypiella dan $H$. armigera dalam choice test selama 30 menit.

\begin{tabular}{lll}
\hline \hline Spesies parasitoid & $P . g 0 s s y p i e l l a$ & H. armigera \\
\hline$T$. armigera (Asembagus) & $3,08=0,72 \mathrm{a}$ & $3,00=0,44 \mathrm{a}$ \\
T. armigera (Lamongan) & $7,73=0,88 \mathrm{a}$ & $1,00=0,36 \mathrm{~b}$ \\
\hline
\end{tabular}

${ }^{1}$ Angka yang didampingi oleh huruf yang berbeda pada baris yang sama menunjukkan perbedaan yang nyata $(P \leq 0,05)$ atas dasar uji Fisher's PLSD

Tabel 6. Lama hidup, kemampuan parasitasi dan survival dari telur - dewasa parasitoid larva Apanteles sp pada larva $P$. gossypiella.

\begin{tabular}{lc}
\hline \hline \multicolumn{1}{c}{ Lama hidup (hari) } & 4,6 hari \\
\hline Kemampuan parasitasi & 31,2 larva \\
Survival parasitoid dari telur - dewasa & $0,1 \%$ \\
\hline
\end{tabular}

Tabel 7. Preferensi parasitoid larva Apanteles sp. terhadap beberapa stadia inang larva P. gossypiella dan C cephaionica dalam uji dengan pilihan dan tanpa pilihan.

\begin{tabular}{lcccc}
\hline \hline \multirow{2}{*}{ Jenis inang } & \multicolumn{2}{c}{ Uji dengan pilihan } & Uji tanpa pilihan \\
\cline { 2 - 5 } & P. gossypiella & C. cephalonica & P. gossypiella & C. cephajonica \\
\hline Instar I & $0,6 \mathrm{a}^{\dagger}$ & $0,0 \mathrm{a}$ & $1.0 \mathrm{a}$ & $1,0 \mathrm{a}$ \\
Instar II & $2,8 \mathrm{C}$ & $1.2 \mathrm{~b}$ & $6,0 \mathrm{C}$ & $5,0 \mathrm{C}$ \\
Instar III & $1,8 \mathrm{~b}$ & $1,2 \mathrm{~b}$ & $3.7 \mathrm{~b}$ & $2.8 \mathrm{~b}$ \\
Instar IV & $0,2 \mathrm{a}$ & $0,0 \mathrm{a}$ & $0,3 \mathrm{a}$ & $0,0 \mathrm{a}$ \\
\hline
\end{tabular}

\footnotetext{
'Angka yang didampingi oleh huruf yang berbeda pada kolom yang sama menunjukkan perbedaan yang nyata
} $(P \leq 0,05)$ atas dasar uji Fisher's PLSD 
tersebut juga dapat digunakan untuk mengendalikan populasi $H$. armigera yang juga merupakan serangga hama penting di kapas dan mulai ditemukan telurnya pada 35-40 hst.

\section{Pelepasan parasitoid telur} Trichogramma dan Trichogrammatoidea untuk mengendalikan P. gossypiella telah banyak dilakukan (Sekhon and Varma, 1983; Pawar and Prasad, 1985; Ahmad et al, 1996; El-Havez and Nada, 2000). Di India, $65 \%$ petani kapas menggunakan parasitoid telur untuk mengendalikan penggerek buah ini (Farkade et al, 1999), sedangkan di Pakistan dilaporkan bahwa penggunaan parasitoid telur ini lebih menguntungkan baik untuk perkebunan luas maupun perkebunan rakyat (Mohyuddin et al., 1997). Dengan demikian, parasitoid telur asal Indonesia dengan potensinya tersebut cukup berpeluang untuk dimanfaatkan dalam program pengendalian $P$. gossypiella di kapas. Teknik perbanyakan massal parasitoid ini secara sederhana telah tersedia (Nurindah, 2002).

Tingkat parasitasi alami larva oleh parasitoidnya dapat mencapai $38 \%$ (Tabel 3). Parasitoid larra P. gosspiel/a yang umum ditemukan adalah Apanteles sp. Parasitoid ini ditemukan di semua daerah survei (Tabel 2) dengan tingkat parasitasi mencapai $24 \%$. Apanteles sp. menyerang larva instar kedua atau ketiga, pada waktu inang sudah terdapat di dalam buah. Proses parasitasi dapat terjadi karena parasitoid ini mempunyai ovipositor yang panjang, sehingga me- mungkinkannya untuk oviposisi pada inang yang terlindung. Apanteles angaleti merupakan parasitoid dominan yang menyerang $P$. gossypiella pada pertanaman kapas di Karnataka, India (Sangareddy and Patil, 1997) dan Punjab (Sekhon and Verma, 1983). Walaupun demikian, parasitoid ini belum pernah digunakan dalam program pengendalian hayati dengan augmentasi. Hal ini disebabkan karena sulitnya parasitoid ini untuk dikembangkan di laboratorium. Olch karena itu, untuk dapat meningkatkan kinerja parasitoid ini sebagai agensia hayati, maka pendekatan yang dapat dilakukan adalah melalui teknik konservasi. Salah satu tindakan konservasi adalah melalui pengelolaan habitat dengan penyianagan terbatas terhadap tanaman-tanaman liar. Telah dilaporkan bahwa parasitoid dari genus Apanteles dapat bertahan hidup lebih baik jika mempunyai akses terhadap bunga Euphorbia birta Nurindah et al, 2002).

Parasitoid larva-pupa yang menyerang $P$. gossypiella adalah Bracbymeria sp. dan satu spesies dari Ichneumonidae (hanya ditemukan di Lamongan) (Tabel 1). Parasitasi alami yang terjadi dapat mencapai 16\% (Tabel 2). Brachymeria sp. juga merupakan parasitoid yang terdapat di semua daerah survei. Sebagai parasitoid larva-pupa, kedua parasitoid ini kurang berpeluang untuk digunakan dalam program pengendalian hayati dengan augmentasi, karena inang yang telah terparasit masih tetap hidup hingga menjadi pupa, sehingga inangnya masih menimbulkan kerusakan pada tanaman. 
Walaupun demikian, parasitoid ini dapat ditingkatkan kinerjanya dengan pendekatan konservasi.

\section{KESIMPULAN}

Parasitoid yang berpotensi tinggi untuk dapat dimanfaatkan dalam program pengendalian hayati $P$. gossypiella $\mathrm{pa-}$ da kapas adalah parasitoid telur $T$. armigera dan $T$. battrat dengan teknik augmentasi yang dilakukan pada saat terjadi infestasi generasi pertama. Parasitoid larva Apanteles sp. dapat ditingkatkan kinerjanya melalui pendekatan konservasi.

\section{DAFTAR PUSTAKA}

Ahmad, X, M. Ashraf, T. Hussain and B.F. Nasrullah. 1996. Significance of pheromones and parasites for the control of corron bollworm. Pahistan Journal of Zoolog, 28:355-357.

Common, I.F.B. 1958. At revision of the pink bollworms of cotton (Pestinophora Busck) (Tepidoptera: Gelechiidac) and related genera in Australia. Aktralian Journal of Zoolog;, 6:268-306.

Cook, M.J.W. 1985. The use of parasitoids for augmentative biolgical control of pests in People's Republic of China. Biocontro/ News and injormation, 6:213-224.

El-Havez, A... and M... Nada. 2000. Augmentation of Trichogrammatoidea batrue Nagaraja in the IP.M programme for control of pink bollworm, Pettinophora gosspiella (Saund.) in Egypt. In Proceedings Belnude Cotron Conferences, Vol. 2, Eds. P. Dogger and D. Rutcher, National. Cotton Council Memphis:1009-1015.

Farkade, B.C., R.D. Ahire, N.R. Patange, and P.S. Ahire. 1999. Extent of adoption of biological pest control in cotton. Journal of Soil and Crops, 9:108-110.

Gordh, G, and J. Ellington. 2001. A review of parasitic Hymenoptera associated with pink bollworm. (manuscript).
Hassan, S.A. 2001. Egg Parasitoid News, No. 16 Aprl 2001. International Organisation of Biological Control.

Henneberry, T.J. and S.E. Naranjo. 1998. Integrated management approches for pink bollworm in the southwestern Lnired States. Integrated PASt Management Retiews. 3:31-52.

Legner, E.F. and R.A. Medved. $19^{-9}$. Influence of parasitic Hymenoptera on the regularion of pink bollworm Peatinophora sos, piella on cotton in the Lower Colorado Dessert. Environmental Entomolog, 8:922-930.

Legner, E.F, and TS. Bollows 2000 Explotation for natural cricmes. It Handloank of Biologial Control. Eds. TS Bellows, T.W. Fisher, L.E. Calragrone. D.L. Dahlsten, G. Gordh, and C.B. Huffaker, pp. 87-102, Academic Press

Mohỵuddin, A.1., G. Jilani, A.G. Khan, A. Hamzi, I. Ahmed and Z. Mahmood. 199" Integrated pest management of major cotton pests by conservation. redistribution and augmentation of narum? cnemies. Pakistan Journal of Zoolog;, 29:293298.

Naranio, S.F. 1993. Life history of Tr.hagramme batrat (Hymenoptera: Trichogrammatadae) an cgg parasitoid of pink bollworm (Lepidoptera: Gelechidae) with emphasis on performance at hgh temperature. Environmental Entomolog, 22:1051-1059.

Nurindah, B.W. Cribb and G. Gordh. 1999. Effects of phrsiological condition and experience on ovipostion behatiour of Tridogramma atstralicum Girualt (Hymenoptera: Trichogrammatidac) on eggs of Helloverpa arnigura Hubner (Lepidoptera: Noctuidae). Anstralian Journal of Entomolog;, 38:104-114.

Nurindah. 2002. Teknik perbanyakan parasitoid telur Trihogramma. Monograf Balittas Xo. 7: Kapas, Buku 2. Balitras, Malang, p. 178 186.

Nurindah, D.A. Sunarto, dan Sujak. 2002. Pengujian bebcrapa tanaman alternatif terhadap keragaan parasitoid dan predator scrangga hama kapas. Laporan Hasil Penelitian Proyek PHT Perkebunan ADB (IPMISECP). Balittas. 20 hal,

Pawar, A.D. and J. Prasad. 1985. Evaluation of some exotic parasites in biocontrol of cotron bollworm in harayana. Indian fourtual of Plan Protection, 13:21-24. 
Rizal, M., D... Sunarto, I G.A.A. Indrayani, Subiyakto dan Socbandrijo. 1999. Dinamika populasi ulat buah merah kapas di Asembagus, Jawa Timur. Prosiding Seminar Nasional Tantangan Entomologi Pada Abad XXI, PEI Cabang Bogor dan Proyek PHT. pp. 231-237.

Sholahuddin. 2001. Penarikan contoh beruntun Pectinophora gassypiella (Saunders) (Lepidoptera: Gelechiidae) pada pertanaman kapas. Desertasi Program Pasca Sarjana Universitas Brawijaya.

Sangareddy, X.K. and B.Y. Patil. 1997. Studies on pink bollworm, Pectinophara gasygitilla (Saunders) incidence and its natural enemies on cotton in Tungabhadra.
Karnataka Journal of Agricultural Sizences, 10:226-228.

Sekhon, B.S. and G.C. Verma. 1983. Parasitoid of Pettinophora gasspiella (Lep.: Gelechiidae) and Earias spp. (Lep.: Nocnuidae) in the Punjab. Entomoplagat 28:45-53.

Tuhan, X.C., A.D. Pawar, and R.S. Arora. 1987. Use of Tribogramma brasiliensis against bollworm in Srinaragar, Rajashran, India. Journal of Advane Zoolog;, 8:131-134.

Zaki, FN. 1985. Reactions of egg parasitoid Trichogramma andescens. Westw, to certain insect sex pheromones. Zeitsibrifl fur Anganandte Entomologie. 99:448-453. 